\title{
MODIS TIME SERIES FOR LAND USE CHANGE DETECTION IN FIELDS OF THE AMAZON SOY MORATORIUM
}

\author{
J. Risso ${ }^{\text {a, }}$, B. F. T. Rudorff ${ }^{\text {a }}$, M. Adami ${ }^{\text {a }}$, A. P. D. Aguiar ${ }^{\text {a }}$, R. M. Freitas ${ }^{\text {a }}$ \\ ${ }^{a}$ National Institute for Space Research (INPE), Av. dos Astronautas, 1.758 São José dos Campos, SP, Brazil - (risso, \\ bernardo,adami,ramon)@dsr.inpe.br; ana.aguiar@inpe.br
}

Commission VIII, WG VIII/6

KEY WORDS: Land Use, Land Cover, Multitemporal, Forestry, Crop

\begin{abstract}
:
A virtual globe to visualize time series of pixels from the MODIS sensor over the South American continent is available in the Internet and was developed at the Brazilian Institute for Space Research. The MODIS images acquired since the year 2000 were transformed to a vegetation index (EVI2, two-band Enhanced Vegetation Index) with pixel size of $250 \mathrm{~m}$. This study aims to use these time series to identify land use changes (LUC) based on the temporal profile of EVI2 values of deforested polygons between 2007 and 2011 within the context of the Soy Moratorium. Deforested polygons were divided in two strata: with and without soy in crop year 2010/11. From the MODIS/EVI2 time series the following classes were identified: forest, degraded forest, total clearing of the area, regrowth of forest, regrowth with pasture, pasture, agriculture, and soy. For stratum 1, the dominant LUC trajectory was: forest - degradation - regrowth / regrowth with pasture. In the second stratum it was observed two main LUC trajectories: 1) forest degraded forest - total clearing of the area - annual crop (rice) - soy; and 2) forest - total clearing of the area - annual crop (rice) soy. For most samples of stratum 2 the LUC trajectory was agriculture (e.g., rice) between total clearing and soy cultivation. These patterns occurred on average over two harvests, which may be considered the necessary time for soil correction and total removal of above ground stumps and roots to enable mechanized soy harvesting. The fast evaluation of one hundred polygons during 11 years was only possible due to the virtual globe to visualize the MODIS time series that proved to be an important tool to improve the understanding of LUC dynamics in the Amazon region.
\end{abstract}

\section{INTRODUCTION}

The majority of the net carbon emissions in Brazil is estimated to come from land use change (LUC), in particular due to the conversion of forest to agricultural land (BRASIL, 2008). During the past few decades the main hotspots of this conversion have been concentrated in the southern and southeastern Amazon regions where most of the expansion of the agricultural frontier takes place (Alves, 2002; Fearnside, 2005; Skole and Tucker, 1993).

Large scale agricultural activity in the Amazon began in the 1970s. During this period and throughout the following decades several governmental programs such as National Integration Program $(P I N)$, Program for Land Redistribution and Stimulation of Agribusiness in the North and Northeast (PROTERRA), and Advance Brazil and were promoted to incentivize colonization, development and integration of the Amazon into the national economy. In addition to these programs the easy credit, the construction of highways, and the vast offering of land at irresistible prices attracted many farmers from southern Brazil (Laurance et al., 2001; Nepstad et al., 2002). The opportunity to guarantee ownership through land tenure or by proof of productive use of the land also attracted farmers and speculators to the Amazon (Hecht et al., 1988, Alston et al., 2000).

Among the government investments for the viability of the agricultural production in this region, programs for genetic improvement and adaptation of soy to low latitude regions were developed by EMBRAPA (Sousa, 1990). With new technologies and seeds adapted to tropical conditions, the cultivated crop area increased rapidly, and soy cultivation became one of the main economic activities, particularly in the state of Mato Grosso. Beginning in the 1990s, the expansion of the agricultural frontier in the Amazon started to be driven by market forces. For example, the demand for meat in the Middle East and Russia, and for soy in China (Fearnside, 2001; Macedo et al., 2012; Nepstad et al., 2006; Morton et al., 2006).

With the increase in global demand for food, which was not entirely met by increases in agricultural productivity, the conversion of forest to agriculture became a market solution and, at the same time, a major environmental problem. This insight is reason of the increase on environmental awareness since the conservation of forest land became critical in order to minimize the effects of global climate change. In this way, deforestation in the Amazon that was initially fomented by public policies started to be severely combated by government and Non-Governmental Organizations (NGOs). Even the market has adopted some measures to contain deforestation. Some of these actions are: 1) the establishment in 2003 of the Action Plan for the Prevention and Control of Deforestation in the Legal Amazon (Plano de Ação para Prevenção e Controle do Desmatamento na Amazônia Legal - PPCDAM) (BRASIL, 2008); 2) the Soy Moratorium in 2006 (Rudorff et al., 2011) and; 3) the Beef Moratorium in 2009 (Boucher et al., 2011).

Slowing down the advance of soy production in recent deforested land in the Amazon has also been the goal of several NGOs since the beginning of the 2000s. Greenpeace stood out by advertising the negative impact of soy produced in deforested land in the Amazon, in front of McDonald's restaurants in Europe. In addition to the protests, Greenpeace 
published a report in 2006 entitled "Eating Up the Amazon". This report contained evidence that soy cultivated in deforested areas of the Amazon biome was exported to Europe and used to feed chicken to produce the "McNuggets" (Greenpeace, 2006).

Given the impact of these actions on public opinion and the questions of European clients about the origin of Brazilian soy, the topic of deforestation began to be part of the soy traders' agenda. In this way, NGOs and Brazilian soy traders initiated a dialogue with the aim of defining a common agenda for stopping the advance of soy into the Amazon rainforest resulting in the Soy Moratorium that was signed on July $24^{\text {th }}$, 2006. This agreement requires that all soy cultivated in deforested areas (legal or illegal) after this date will not be commercialized by any company linked to the Brazilian Association of Vegetable Oil Industries (Associação Brasileira das Indústrias de Óleo Vegetal - ABIOVE) and the National Association of Cereal Exporters (Associação Nacional dos Exportadores de Cereais - ANEC). The Soy Moratorium has been renewed annually and, since 2009, satellite images are being used for monitoring soy cultivation in deforested areas mapped by the Program for the Calculation of Deforestation in the Amazon (Programa de Cálculo do Desflorestamento da Amazônia - PRODES) (Rudorff et al., 2011).

The monitoring method is based on the EVI2 time series from the MODIS sensor and the Crop Enhancement Index (CEI) approach (Rizzi et al., 2009). At the same time, images with improved spatial resolution from the AWIFS, LISS3, TM and ETM+ sensors are used to better identify and delineate the soy plantations within the deforested polygons (Rudorff et al., 2012). In some instances the deforestation date is contested by the farmer and the visualization tool for EVI2 time series developed by INPE (Freitas et al., 2011) is used, together with TM images, to ensure the correct deforestation date whenever there is a conflict between PRODES data and the farmer argument. The visualization tool has been used to determine the exact period in which deforestation occurred. In addition, it allows the identification of various LUC patterns through the seasonal analyses of terrestrial targets (Adami et al., 2012). In this sense, the objective of this work is to use the MODIS/EVI2 time series to identify the LUC patterns and trajectories of deforested areas within the Soy Moratorium context.

\section{STUDY AREA}

The study area is comprised by the Soy Moratorium polygons selected during the fourth year of monitoring (crop year 2010/11). The selected polygons are from the PRODES years of 2007 to 2010 within municipalities that produced more than 5,000 ha of soy each in the previous crop year, and with an area higher than 25 ha (Rudorff et al., 2011). Figure 1 indicates the location of the Amazon biome and the states and municipalities monitored in crop year 2010/11.

In crop year 2010/11, 3,571 polygons with a total area of 375,500 ha were monitored. Of this total, soy plantations were found in 146 polygons corresponding to an area of 11,698 ha.

\section{MATERIAL AND METHODS}

The 3,571 deforested polygons were pre-evaluated with regards to size and compactness criteria to exclude those polygons that are too narrow or irregular. The compactness index (CI) is the ratio between the perimeter and the square root of the area of the polygon. Higher IC values indicate more irregular geometries, while lower IC values indicate more regular geometries. A polygons to be selected should have IC less than 9 for area greater than 40 ha, or IC less than 6 for area smaller than 40 ha. This procedure selected 1,971 polygons without soy and 91 polygons with soy. A subsample of 50 polygons was selected from each stratum: with and without soy.

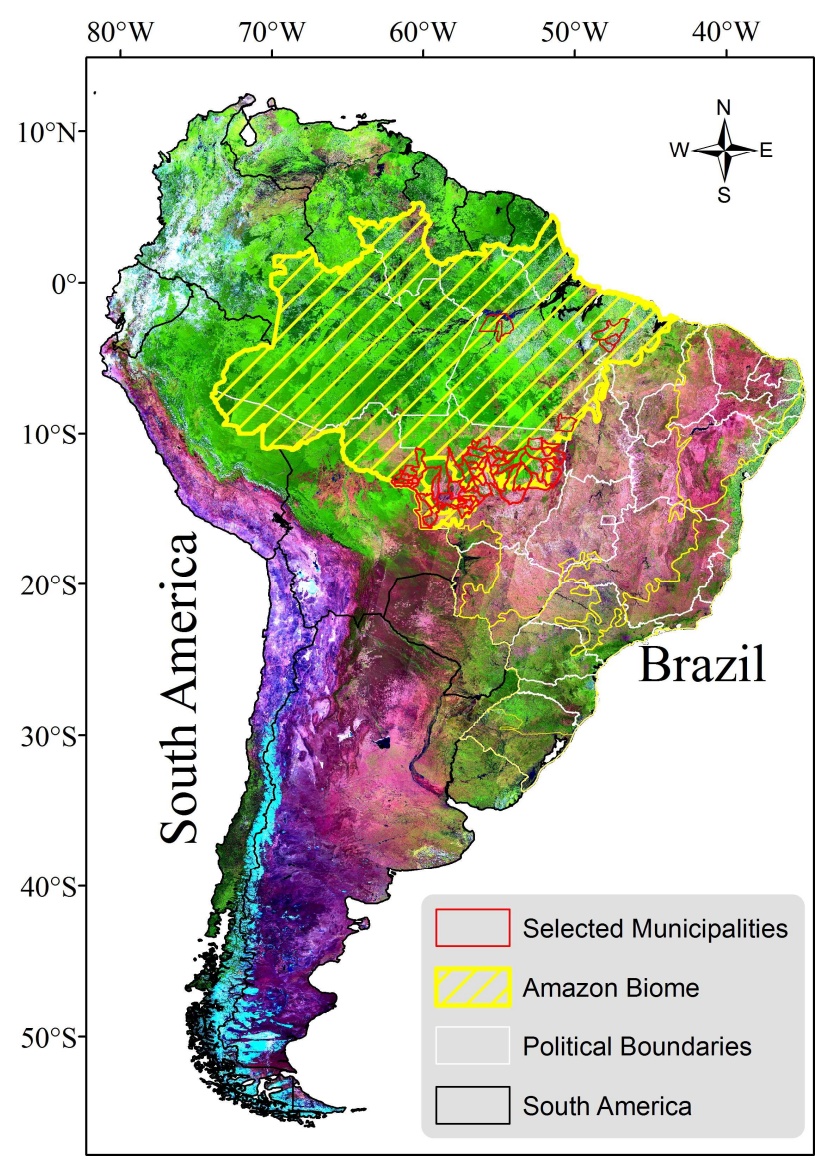

Figure 1. Location of the study area. Adapted from Rudorff et al. (2011).

In the next step, the subsampled polygons were evaluated with respect to LUC homogeneity. Very heterogeneous polygons represented an additional difficulty in the characterization of LUC patterns and transitions after deforestation. For the polygons without soy (first stratum), the evaluation was conducted based on variations in the EVI2 temporal profile of several MODIS pixels within the polygon. Each polygon rejected in this evaluation phase was replaced by another polygon. For the polygons with soy (second stratum) the homogeneity was evaluated based on land use information acquired from the aerial survey and available at: <http://www.abiove.com.br/ss_relatoriouso10_br.asp>.

After the final selection of the 50 polygons from each stratum a central pixel of each polygon was selected to perform the MODIS/EVI2 time series profile analyses using the MODIS Time Series Visualization for Land Use and Cover Analysis (<https://www.dsr.inpe.br/laf/series/>) of the Remote Sensing Time Series Virtual Laboratory developed to integrate a large 
amount of information from the MODIS image time series (Freitas et al., 2011).

Historical monthly precipitation data from the Tropical Rainfall Measuring Mission (TRMM) and information from the Google Maps API digital elevation model over two concentric circles with adjustable radii around the pixel are also available for each MODIS pixel of the time series (Freitas et al., 2011). To locate the selected polygon of interest in the Google Maps Virtual Globe it is sufficient to indicate the coordinates (latitude and longitude).

\subsection{Classification of the EVI2 temporal profile}

The LUC classification using the EVI2 profiles is conducted based on the previous knowledge of the temporal patterns of the main targets within the deforested polygons. Figure 2 presents some typical EVI2 profiles for the region, which allows identifying some of the LUC patterns and transitions.

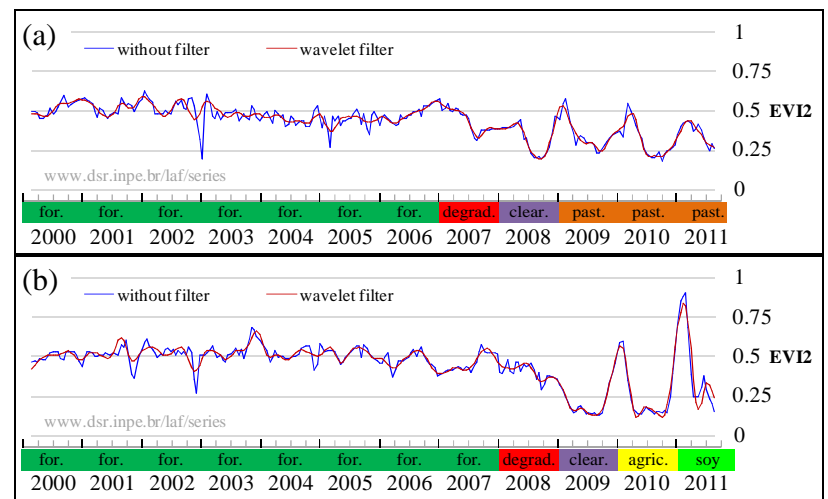

Figure 2. EVI2 temporal profile for two deforested polygons: (a) Forest from 2000 to 2006, transition from forest to pasture in 2007 and 2008, and pasture after 2009; and (b) Forest from 2000 to 2007, transition from forest to bare soil in 2008 and 2009 followed by agriculture use in 2010 and soy in 2011. Abbreviations: for. (forest); degrad. (degradation); clear. (total clearing of the area); past. (pasture); agric. (agriculture).

Previous works such as Galford et al. (2008), Freitas et al. (2011), and Adami et al. (2012) presented some examples of typical temporal behavior of MODIS vegetation indices for pasture and agriculture land. A common characteristic of these targets is the pronounced seasonality. The amplitude is more evident for annual crops, while the duration of the cycle is longer for pasture. These characteristics allow the differentiation of forest, which has low seasonal variation throughout the year (Figure 2).

In the off-season the dominant spectral response for agriculture is bare soil/dry straw with low EVI2 values. During the crop growth period a rapid increase of green vegetation causes the EVI2 to peak reaching values as high as 0.9 at maximum canopy development, especially on soy crops . Furthermore, the agricultural areas tend to have a rapid increase in EVI2 values during the crop development period, followed by a strong drop, creating a more narrow profile, aiding in its identification. In this work, areas with high seasonal variation, narrow profiles and EVI2 peaks lower than 0.7 were classified as agriculture. This class tends to include rice (predominantly), corn (more common in Pará), and in some instances less developed soy fields. Profiles with EVI2 $\geq 0.7$ will be classified as soy. The threshold of 0.7 was established after a detailed evaluation of the 194 polygons with soy in crop year 2010/11. Several of the aerial surveyed polygons presented corn and rice fields, which were used to define the threshold.

For pasture land, there is less increase in EVI2 values because the canopy tends to be less homogeneous and the soil cover, in the majority of cases, is not complete. This is further enhanced by the low investments in pasture renewal, typical for extensive cattle production zones. The presence of cattle herd, which consumes green biomass before the maximum pasture vegetative peak, also contributes to the heterogeneity of the spectral response. In addition, the predominance of grass with erect leaf geometry lowers the EVI2 values. Therefore, agriculture and pasture land are easily identified in the temporal EVI2 profiles, as can be seen in Figure 2.

In some isolated cases of rice cultivation amid piles of trunks and above ground roots, during one to three crop years after the clearing of a former forested land, the temporal profile of the EVI2 can be similar to pasture.

The degraded forest pattern is observed under selective logging and/or fire occurrence. This pattern is observed during the deforestation process before the area has been totally cleared. When the clearing of the area is not completed an intensive vegetation regrowth can be observed in the rainy season (Lima et al., 2012). In this work, these areas will be classified as regrowth. Although they are less common, some areas classified by PRODES as deforested may present regrowth after the total clearing of the area.

Eventually, the LUC trajectories will be traced and the most frequent patterns of transition after the deforestation process will be indicated for the polygons with and without soy plantations. For the soy polygons the average time between deforestation and soy plantation will also be evaluated to characterizing the most common trajectories of the soy polygons that are not in agreement with the Soy Moratorium.

\section{RESULTS AND DISCUSSION}

\section{Areas without soy in crop year 2010/11}

The 50 selected polygons without soy in crop year 2010/11 were classified according to the year of deforestation detected by PRODES. Twelve polygons (24\%) were from deforestation detected in 2007; 32 polygons (64\%) from 2008; 4 polygons (8\%) from 2009; and 2 polygons (4\%) from 2010. Most of the polygons $(68 \%)$ were from Mato Grosso, followed by Pará (26\%) and Rondônia (6\%). Forty polygons $(80 \%)$ presented significant degradation prior to the deforestation process. This finding agrees with Uhl et al. (1991), Nepstad et al. (1999) and Sorrensen (2004), which report that the forest degradation in the Amazon region is a common practice prior to the deforestation process, either by selective logging or fire.

Figure 3 shows that 38 polygons $(76 \%)$ presented indications of regrowth in 2011. For 19 of these polygons the information from the temporal profiles was not enough to distinguish regrowth from pasture. Despite the evidence of regrowth, the identification of small seasonal cycles could be associated with fire occurrence in the dry season, a common practice in the region for pasture renewal (Lima et al., 2012). Nevertheless, if 
they are exploited with cattle, these represent low productivity pasture areas. This occurs due to the elevated soil cover with natural regrowth (excessive shading) and the difficulties of intensive management practices that imply the necessity of mechanization (Numata et al., 2007). Thus, the most common LUC trajectory was from forest to degraded forest, and to deforestation with typical regrowth and regrowth with pasture.

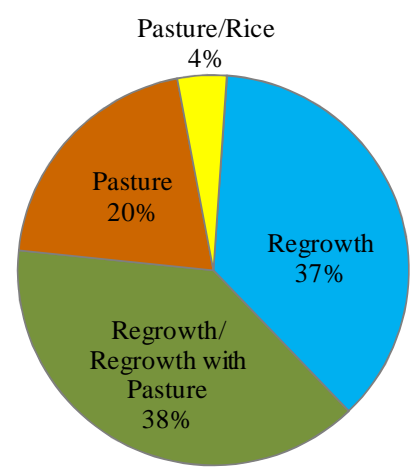

Figure 3. Distribution of the LUC classes in 2011 in deforested polygons without soy.

According to data from the TerraClass project, which classified the land use cover in 2008 for the total deforested PRODES presented in $2007,46.7 \%$ of the deforestations were with clean pasture. The natural regrowth class covered $21 \%$ of the deforested areas and regrowth with pasture covered $8.7 \%$. Taking into account that annual crop occupied only $4.9 \%$ of the deforested area, there was a significant discrepancy between these results and those originating from TerraClass for the classes of pasture and regrowth. It is likely that these differences are due to the fact that in this work, only the first few years after deforestation were evaluated, while TerraClass considered the historical deforestation since 1988. Therefore, part of the recently deforested areas currently in regrowth process or covered with pasture with regrowth could still be converted to clear pasture during the coming years.

Another observation for the polygons without soy is that, in 12 polygons $(24.5 \%)$ did not occurred the total clearing of the area after the shallow cut pointed by PRODES. In all these cases, it was observed that subsequent pattern was clear pasture. This result is coherent because the deforestation process is a costly one and the investment made by the producer is only justified when the goal is to use the area more intensively for either cattle raise or agriculture.

It is also interesting to observe that only 2 polygons were directly converted to agriculture in 2011 . In the event that the conversion actually occurred, the low EVI2 peak observed in this crop year is likely to be associated with the cultivation of rice, since legumes such as soy tend to have elevated EVI2 peaks at maximum crop development.

\section{Areas with soy in crop year 2010/11}

Out of the 50 selected polygons with soy in crop year 2010/11, $39(78 \%)$ were from Mato Grosso, 11 (22\%) from Pará and none from Rondônia. The soy selected polygons were also classified according to the year of deforestation detected by PRODES. Thirty-two polygons (64\%) were from deforestation detected in 2007; 13 polygons (26\%) from 2008; 5 polygons $(10 \%)$ from 2009; and none from 2010 indicating that the entrance of soy soon after deforestation is not a common practice adopted by the farmers in the region. However, the 5 polygons from 2009 were directly converted to soy.

Rivero et al. (2009) and Brown et al. (2005) related that even though the areas had been deforested with the objective of soy cultivation, this transition generally did not occur immediately after deforestation. There is a transition process in which the cultivation of rice is a common practice during a period which can vary from 1 to 3 crop years after deforestation. Our results showed that for more than $70 \%$ of the analyzed polygons the soy crop was likely to be preceded by rice crop. Two main factors contribute to this commonly used transition. The first is the lower demands for soil fertility and $\mathrm{pH}$ for rice cultivation, which is corrected by the addition of chemical fertilizers and limestone. The second is related to the difficulties of mechanized harvesting of the crops, since it is a recently deforested area, where generally many irregularities exist in the terrain, caused by the pulling of stumps or the occurrence of protruding roots. This hampers the operation of combine harvester, especially for soy, since this is conducted with platforms close to the ground. On the other hand, for rice cultivation, the harvesting platform remains higher above ground (20 to $30 \mathrm{~cm}$ ), avoiding possible damage to the cutting bar of the platform due to contact with roots or stumps that can damage the combine harvester. During the rice cultivation new stump and protruding root suppression operations are conducted in a way to permit the entrance of soy in following years.

Nearly half of the soy polygons showed some indication of forest degradation prior to the deforestation process which was much lower than the $80 \%$ of degradation observed for the polygons without soy. This might be motivated by the location of the agricultural areas. In other words, the current centers of agricultural production are concentrated in the oldest regions of colonization of the Amazon region, where timber harvesting by means of selective logging could have occurred before the year 2000. In addition, when the farmer makes a decision to increase his cultivated area over forest land, this tends to occur in a more direct way. The phase of induced fires, for example, during several years before the deforestation could not occur if the decision to increase the agricultural area is associated with an instantly attractive agricultural commodity market price. It was also possible to identify the year in which the total clearing of the area was made in almost all cases, except for two polygons. In approximately $20 \%$ of the cases, there were signs of the beginning of the regrowth process after the clearing of the area, which in none of the cases exceeded two years. Hence, there is a transitional pattern which can occur in some cases when the farmer does not finalize the preparation of the soil for cultivation, immediately after the total clearing of the area, concluding the preparation of the soil throughout the following years.

Thus, in the polygons with soy in crop year 2010/11 it was possible to identify and trace two main LUC trajectories: 1) forest - forest degradation - total clearing of the area agricultural cultivation (predominantly rice) - soy; 2) forest total clearing of the area - agricultural cultivation (predominantly rice) - soy. The average duration of the transitional cultivation of an annual crop such as rice was two crop years from total clearing to soy cultivation. It should be noted that in contrast to the polygons without soy, the occurrence of soy basically defines the end of the LUC 
trajectory under the current economy, since it is a stable land use and less reversible (Lambin et al., 2003).

\section{CONCLUSIONS}

The analysis of the spectral-temporal profiles of EVI2 from MODIS permitted the identification of the principal LUC patterns and transitions of the Soy Moratorium polygons. The evalution of a hundred different areas during 11 years was only possible thanks to the information and functionalities available in the MODIS Time Series Visualization for Land Use and Cover (Freitas et al., 2011).

For the first stratum, i.e., the polygons not converted to soy until 2011, characteristic features of forest degradation before the deforestation process were identified in $80 \%$ of the polygons. However, in the majority of them, total clearing of the area for more intensive use was not confirmed. In this group, occurrences of the regrowth process predominated in 2011, in which part of these areas could also be exploited with extensive cattle raising during the regrowth process. The LUC trajectory with the highest occurrence in this strata was: forest degradation - regrowth/regrowth with pasture.

Those converted to soy in 2011, pertaining to stratum 2, it was possible the identification of the moment of total clearing of the forest in nearly all of the cases as a marked characteristic. In addition, the presence of the agricultural class as a transitional LUC pattern between the total clearing of the area and the definitive planting of soy occurred in the vast majority of cases. This pattern had an average duration of two harvests, considered by the farmer to be a sufficient period for the correction and preparation of the soil for the entrance of soy. Finally, the two predominant LUC trajectories in this stratum were: 1) forest - forest degradation - total clearing of the area agricultural cultivation (predominantly rice) - soy; 2) forest total clearing of the area - agricultural cultivation (predominantly rice) - soy.

\section{REFERENCES}

Adami M., Rudorff B.F.T., Freitas R.M., Aguiar D.A., Sugawara L.M., Mello M.P, 2012. Remote Sensing Time Series to Evaluate Direct Land Use Change of Recent Expanded Sugarcane Crop in Brazil. Sustainability, 4(4), pp. 574-585.

Alston, L.J., Libecap, G.D.,Mueller, B., 2000. Land Reform Policies, the Sources of Violent Conflict, and Implications for Deforestation in the Brazilian Amazon. Journal of Environmental Economics and Management, 39(2), pp. 162188.

Alves, D.S., 2002. Space-time dynamics of deforestation in Brazilian Amazônia. International Journal of Remote Sensing, 23(14), pp. 2903-2908.

Boucher, D., Elias, P., Lininger, K., May-Tobin, C., Roquemore, S., Saxon, E., 2011. The Root of the Problem: What's Driving Tropical Deforestation Today? Union of Concerned Scientists, Cambridge, MA. http://www.ucsusa.org/assets/documents/global_warming/UCS_ RootoftheProblem_DriversofDeforestation_FullReport.pdf (10 Mar. 2012).
BRASIL - Comitê Interministerial Sobre Mudança no Clima. Versão para Consulta Pública, 2008. http://www.mma.gov.br/estruturas/169/_arquivos/169_2909200 8073244.pdf (14 Mar. 2012).

Brown, J.C., Koeppe, M., Coles, B.,Price, K.P., 2005. Soybean production and conversion of tropical forest in the Brazilian Amazon: The case of Vilhena, Rondonia. Ambio, 34(6), pp. 462-469.

Fearnside, P.M., 2001. Soybean cultivation as a threat to the environment in Brazil. Environmental Conservation, 28(01), pp. 23-38.

Fearnside, P.M., 2005. Deforestation in Brazilian Amazonia: History, Rates, and Consequences. Conservation Biology, 19(3), pp. 680-688.

Freitas, R.M.d., Arai, E., Adami, M., Ferreira, A.S., Sato, F.Y., Shimabukuro, Y.E., Rosa, R.R., Anderson, L.O., Rudorff, B.F.T., 2011. Virtual laboratory of remote sensing time series: visualization of MODIS EVI2 data set over South America JCIS - Journal of Computational Interdisciplinary Sciences, 2(1), pp. 57-68.

Galford, G.L., Mustard, J.F., Melillo, J., Gendrin, A., Cerri, C.C., Cerri, C.E.P., 2008. Wavelet analysis of MODIS time series to detect expansion and intensification of row-crop agriculture in Brazil. Remote Sensing of Environment, 112(2), pp. 576-587.

GREENPEACE, 2006. Eating up the Amazon, Greenpeace International, Amsterdam, Holland. http://www.greenpeace.org/international/Global/international/pl anet-2/report/2006/7/eating-up-the-amazon.pdf (12 Mar. 2012)

Hecht, S. B., Norgaard, R. B., Possio, C., 1988. The economics of cattle ranching in eastern Amazonia. Interciencia, 13 (5), pp. 233-240.

IBGE. Instituto Brasileiro de Geografia e Estatística. Sistema de recuperação automática. Censo Demográfico. http://www.sidra.ibge.gov.br/bda/tabela/listabl.asp? $\mathrm{z}=\mathrm{t} \& 0=25 \&$ $\mathrm{i}=\mathrm{P} \& \mathrm{c}=3145$ (27 feb. 2012).

Lambin, E.F., Geist, H.J.,Lepers, E., 2003. Dynamics of landuse and land-cover change in tropical regions. Annual Review of Environment and Resources, 28(1), pp. 205-241.

Laurance, W.F., Cochrane, M.A., Bergen, S., Fearnside, P.M., Delam ̃̃'nica, P., Barber, C., D'Angelo, S.,Fernandes, T., 2001. The Future of the Brazilian Amazon. Science, 291(5503), pp. 438-439.

Lima, A., Silva, T.S.F., Aragão, L.E.O.e.C.d., Feitas, R.M.d., Adami, M., Formaggio, A.R.,Shimabukuro, Y.E., 2012. Land use and land cover changes determine the spatial relationship between fire and deforestation in the Brazilian Amazon. Applied Geography, 34(0), pp. 239-246.

Macedo, M.N., DeFries, R.S., Morton, D.C., Stickler, C.M., Galford, G.L.,Shimabukuro, Y.E., 2012. Decoupling of deforestation and soy production in the southern Amazon during the late 2000s. Proceedings of the National Academy of Sciences, 109(4), pp. 1341-1346. 
Nepstad, D.C., Verssimo, A., Alencar, A., Nobre, C., Lima, E., Lefebvre, P., Schlesinger, P., Potter, C., Moutinho, P., Mendoza, E., Cochrane, M.,Brooks, V., 1999. Large-scale impoverishment of Amazonian forests by logging and fire. Nature, 398(6727), pp. 505-508.

Nepstad, D., McGrath, D., Alencar, A., Barros, A.C., Carvalho, G., Santilli, M.,Vera Diaz, M.d.C., 2002. Frontier Governance in Amazonia. Science, 295(5555), pp. 629-631.

Nepstad, D., Stickler, C., Almeida, O., 2006. Globalization of the Amazon Soy and Beef Industries: Opportunities for Conservation. Conservation Biology, 20(6), pp. 1595-1603.

Numata, I., Roberts, D.A., Chadwick, O.A., Schimel, J., Sampaio, F.R., Leonidas, F.C.,Soares, J.o.V., 2007. Characterization of pasture biophysical properties and the impact of grazing intensity using remotely sensed data. Remote Sensing of Environment, 109(3), pp. 314-327.

Rivero, S., Almeida, O., Avila, S., Oliveira, W., 2009. Pecuária e desmatamento: uma análise das principais causas diretas do desmatamento na Amazônia. Nova economia, 19(1), pp. 41-66.

Rizzi, R., Risso, J., Epiphanio, R.D.V., Rudorff, B.F.T., Formaggio, A.R., Shimabukuro, Y.E., Fernandes, S.L., 2009. Estimativa da área de soja no Mato Grosso por meio de imagens MODIS. In: Anais do Simpósio Brasileiro de Sensoriamento Remoto. Natal, Brazil. INPE, XIV, pp. 387-394.

Rudorff, B.F.T., Adami, M., Aguiar, D.A., Moreira, M.A., Mello, M.P., Fabiani, L., Amaral, D.F., Pires, B.M., 2011. The Soy Moratorium in the Amazon Biome Monitored by Remote Sensing Images. Remote Sensing, 3, pp. 185-202.

Rudorff, B., Adami, M., Risso, J., Aguiar, D., Pires, B., Amaral, D., Fabiani, L., Cecarelli, I., 2011. Remote Sensing Images to Detect Soy Plantations in the Amazon Biome - the Soy Moratorium Initiative. In: Proceedings of the 1st World Sustainability Forum, 1-30 November 2011; Sciforum Electronic Conferences Series.

Skole, D., Tucker, C., 1993. Tropical Deforestation and Habitat Fragmentation in the Amazon: Satellite Data from 1978 to 1988. Science, 260(5116), pp. 1905-1910.

Sorrensen, C., 2004. Contributions of fire use study to land use/cover change frameworks: Understanding landscape change in agricultural frontiers. Human Ecology, 32(4), pp. 395-420.

Sousa, I.S.F, 1990. Condicionantes da modernização da soja no Brasil. Revista de Economia e Sociologia Rural, Brasília, 28(2), pp. 175-212.

Uhl, C., Veríssimo, A., Mattos, M.M., Brandino, Z., Guimarães Vieira, I.C.1., 1991. Social, economic, and ecological consequences of selective logging in an Amazon frontier: the case of Tailândia. Forest Ecology and Management, 46(34), pp. 243-273. 